\title{
"An End to a Means": How DNA-End Structure Shapes the Double-Strand Break Repair Process
}

\author{
Almudena Serrano-Benítez ${ }^{1}$, Felipe Cortés-Ledesma ${ }^{1,2 *}$ and Jose F. Ruiz ${ }^{1,3}$ \\ ${ }^{1}$ Andalusian Center of Molecular Biology and Regenerative Medicine (CABIMER-CSIC-University of Seville-Pablo de Olavide \\ University), Seville, Spain, ${ }^{2}$ Topology and DNA breaks Group, Spanish National Cancer Research Center, Madrid, Spain, \\ ${ }^{3}$ Department of Plant Biochemistry and Molecular Biology, University of Seville, Seville, Spain
}

\section{OPEN ACCESS}

Edited by:

Sergio Fernandes De Almeida, Faculty of Medicine, University of Lisbon, Portugal

Reviewed by:

Lawrence Povirk,

Virginia Commonwealth University,

United States

Katja Lammens,

Ludwig Maximilian University of

Munich, Germany

*Correspondence:

Felipe Cortés-Ledesma fcortes@cnio.es

Specialty section

This article was submitted to Cellular Biochemistry

a section of the journal

Frontiers in Molecular Biosciences

Received: 10 October 2019 Accepted: 11 December 2019

Published: 10 January 2020

Citation:

Serrano-Benítez A, Cortés-Ledesma F and Ruiz JF (2020) "An End to a Means": How DNA-End Structure Shapes the Double-Strand Break

Repair Process.

Front. Mol. Biosci. 6:153. doi: 10.3389/fmolb.2019.00153
Endogenously-arising DNA double-strand breaks (DSBs) rarely harbor canonical 5'-phosphate, 3'-hydroxyl moieties at the ends, which are, regardless of the pathway used, ultimately required for their repair. Cells are therefore endowed with a wide variety of enzymes that can deal with these chemical and structural variations and guarantee the formation of ligatable termini. An important distinction is whether the ends are directly "unblocked" by specific enzymatic activities without affecting the integrity of the DNA molecule and its sequence, or whether they are "processed" by unspecific nucleases that remove nucleotides from the termini. DNA end structure and configuration, therefore, shape the repair process, its requirements, and, importantly, its final outcome. Thus, the molecular mechanisms that coordinate and integrate the cellular response to blocked DSBs, although still largely unexplored, can be particularly relevant for maintaining genome integrity and avoiding malignant transformation and cancer.

Keywords: DNA double strand break (DSB), Non-homologous DNA end joining, ATM, DNA-PK catalytic subunit, genome instability

Double-strand breaks (DSBs) are the most devastating lesion that DNA molecule can suffer. Indeed, they can cause dangerous chromosomal rearrangements or even cell death if they are not properly repaired. In general terms, there are two conceptually different pathways to repair DSBs that can be divided into those that use homologous sequences-either a sister chromatid or another sequence elsewhere in the genome-as a template in the repair (homologous recombination, HR), and those that directly rejoin the ends, without any template requirement (Lieber, 2008; San Filippo et al., 2008; Pannunzio et al., 2018), regardless of whether using minimal (non-homologous end-joining, NHEJ) or more extensive (microhomology-mediated end-joining, MMEJ) microhomologies to stabilize the junctions. Despite the general intrinsic diploidy of somatic mammalian cells, HR rarely uses the homologous chromosome as a template for DSB repair (Johnson, 2000). Consequently, HR is mostly restricted to late S/G2 phase, when a sister chromatid is available, whereas NHEJ can operate in any phase of the cell cycle. Besides this global distinction, there are additional peculiarities of DSB repair mechanisms based on the specific nature of each DNA lesion, specifically when it comes to the chemical configuration of the broken DNA ends. In this regard, since the HR will use the information of an intact template for repair (San Filippo et al., 2008), the ends of the break, both 5' and $3^{\prime}$, can be extensively degraded without compromising an efficient reconstitution of the initially lost DNA sequences. In contrast, the chemical modifications of DSB ends, and how these are solved, are pivotal in the NHEJ process and final repair outcome. It is therefore of great interest to understand how DSBs harboring complex DNA ends are repaired in the G1 phase of the cell cycle, during which HR is strongly limited. 


\section{THE NHEJ PROCESS}

The starting point of the NHEJ process takes place with the recognition and binding of double stranded DNA ends by the KU70/80 heterodimer, which occurs in an extraordinarily efficient manner due to its abundance and its strong avidity for this type of DNA substrate. DNA-bound KU heterodimer, in turn, recruits DNA-PKcs to form the DNA-PK holoenzyme, so that the two DNA-PKcs molecules bound to opposing sides of the DSB can interact one each other, contributing to synapsis of broken DNA ends (Meek et al., 2008; Neal and Meek, 2011). The DNA-PK complex is the main regulator of the NHEJ process, coordinating the recruitment of downstream NHEJ accessory factors, such as X-ray cross complementing group 4 (XRCC4), XRCC4-like factor/Cernunnos (XLF), or Paralog of XRCC4 and XLF (PAXX), and DNA ligase IV (LIG4), which contribute to the proper pairing of DSB ends and perform the final ligation of the break (Kakarougkas and Jeggo, 2014; Ochi et al., 2015; Conlin et al., 2017). In vertebrates, NHEJ further evolved an end processing capacity that allows for the repair of complex ends (e.g., hairpins), and which is also, in part, regulated by DNA-PK, as will be discussed below.

\section{RELEVANCE OF END STRUCTURE AND CONFIGURATION DURING NHEJ}

It can be claimed that the only essential step of NHEJ process is the ligation of one of the DNA strands of the DSB (Waters et al., 2014). During this process, LIG4 activity requires compatible ends harboring canonical $5^{\prime}$-phosphate and $3^{\prime}$ hydroxyl termini. However, DSBs often have complex ends with chemical modifications or structures that do not allow straightforward joining of the termini, so they can be considered as blocked ends (Figure 1). These chemical variations can be sensed by LIG4 through the disruption of its catalytic cycle (Reid et al., 2017). Therefore, when DSBs harbor non-canonical chemical structures at the ends, they must be restored to conventional $5^{\prime}$-phosphate and $3^{\prime}$-hydroxyl termini so that DNA ligation can take place. There are two conceptually different ways by which these non-canonical DNA ends can be converted into ligatable substrates (Figure 1). On the one hand, cells have a variety of enzymes to directly restore the canonical chemical structure. Given that this event does not involve any sequence modification, it can be simply considered as an "unblocking" process. On the other hand, under certain circumstances, such as the presence of complex lesions, unblocking activities may be compromised or overwhelmed, resulting in DSBs that require additional "end processing" by the action of nucleases that cleave DNA sequence from the ends to remove the chemical modifications (Figure 1). Regarding unblocking, there is a large number of factors with different enzymatic activities that are available for this process during NHEJ (Figure 2), such as tyrosyl-DNA phosphodiesterases 1 and 2 (TDP1 and TDP2, respectively), polynucleotide kinase (PNKP), Aprataxin, and even KU. This, in turn, reflects the wide variety of damaged termini that can arise, as each of these factors removes specific chemical modifications at DNA ends (Povirk, 2012; Andres et al., 2015). These unblocking activities are essential in NHEJ, since they are responsible for facilitating accurate religation of the breaks, as opposed to the processing of DNA ends that may involve nucleotide loss or gain and, therefore, sequence modification. Interestingly, ionizing radiation, which is a common and wellestablished source of DSBs, mostly induces blocked termini with heterogeneous end structures. Damage occurs either directly, by high-energy particle collision with DNA, or indirectly, when these particles split water molecules leading to dangerous free radicals; in both cases this mainly results in breakage of the sugar backbone, and therefore needs to be processed, necessarily leading to loss of one nucleotide from the termini (Reisz et al., 2014).

Another aspect to highlight in NHEJ is the possible incompatibility among DSBs to be repaired due to the absence of sequence complementarity of DNA ends. This situation may occur when DSB ends have small protuberances, either with $5^{\prime}$ or $3^{\prime}$ polarity. The short stretches of single stranded DNA of these overhangs may be compatible (either fully or partially complementary sequences) or not. It has been shown that LIG4 can ligate across short gaps or rejoin several incompatible DNA end configurations that do not share even 1-bp of terminal microhomology (Gu et al., 2007). For this scenarios, NHEJ also takes advantage of several processing enzymes that can modify DNA ends until they become ligatable substrates (Strande et al., 2012). In this way, single-stranded DNA overhangs (as also may happen with blunt ends) can be trimmed by nucleases such as ARTEMIS giving rise to small gaps than can be efficiently filled-in by specialized X family DNA polymerases (see below) (Mahajan et al., 2002; Lee J. W. et al., 2004; Ma et al., 2004; McElhinny et al., 2005; Capp et al., 2007; Lieber, 2010). It is worth noting that noncomplementary DNA ends are indeed the most likely result of end processing at initially chemically modified structures.

\section{NHEJ: AN ITERATIVE VS A HIERARCHICAL PROCESS}

Although NHEJ is generally considered a single DNA repair pathway, a wide variety of factors are needed and different subroutes can be distinguished depending on the different DSB end configurations (Pannunzio et al., 2018). In addition, there is still important debate about how these NHEJ accessory factors actually operate, and, in this sense, two apparently antagonistic positions can now be distinguished. On the one hand, some authors propose that NHEJ factors operate in an iterative way without an established order (Gu and Lieber, 2008; Lieber, 2008; Gu et al., 2010). This model highlights the flexibility of the NHEJ process and explains the diversity of repair products generated from the same type of DSB. The iterative nature of this process implies that multiple NHEJ components can act on the same DSB during multiple consecutive rounds of processing and that the involvement of factors is not mutually exclusive to the usage of other ones, all of them remaining active as long as the DSB continues unrepaired. On the other hand, other authors propose that there is a hierarchy in NHEJ, by which cells give precedence 


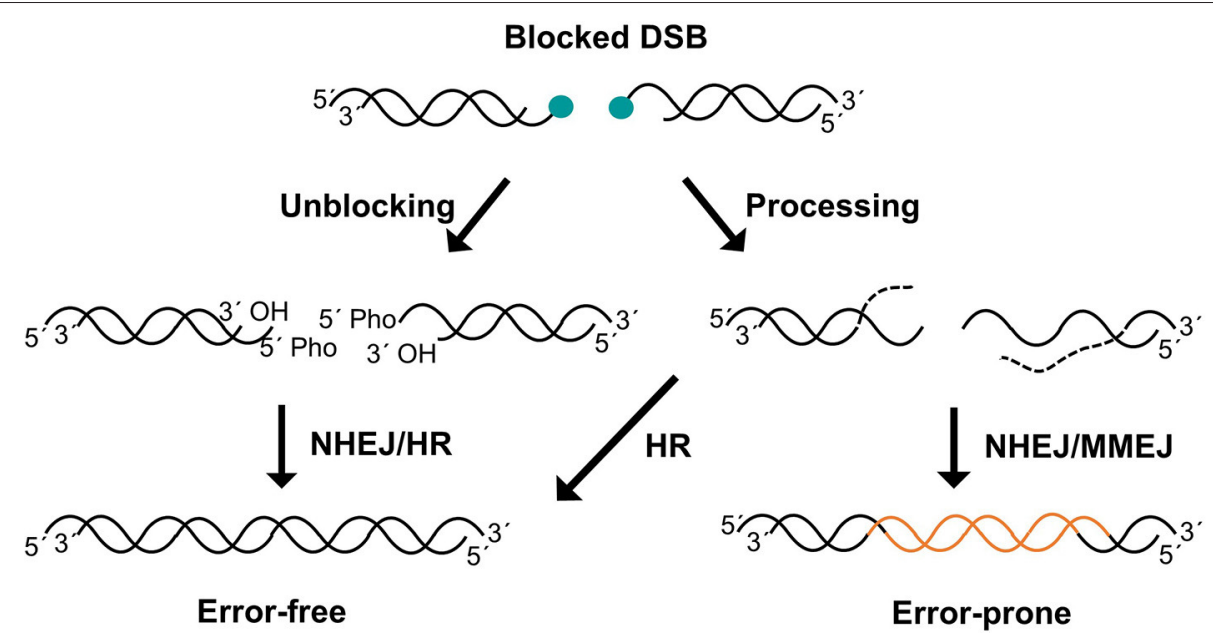

FIGURE 1 | Unblocking and processing of DSBs. Unblocking pathways directly convert ends into 5'-phospahte and 3'-hydroxyl but the nucleotide sequence remains intact, promoting error-free repair (left). Processing can also facilitate blocked DSBs repair removing aberrant structures from DNA ends by nucleotide trimming (right). This pathway can lead to error-prone repair when non-templated repair pathways such as NHEJ or MMEJ are used. $5^{\prime}$ blocks are depicted but similar situations could be generated on $3^{\prime}$ ends.

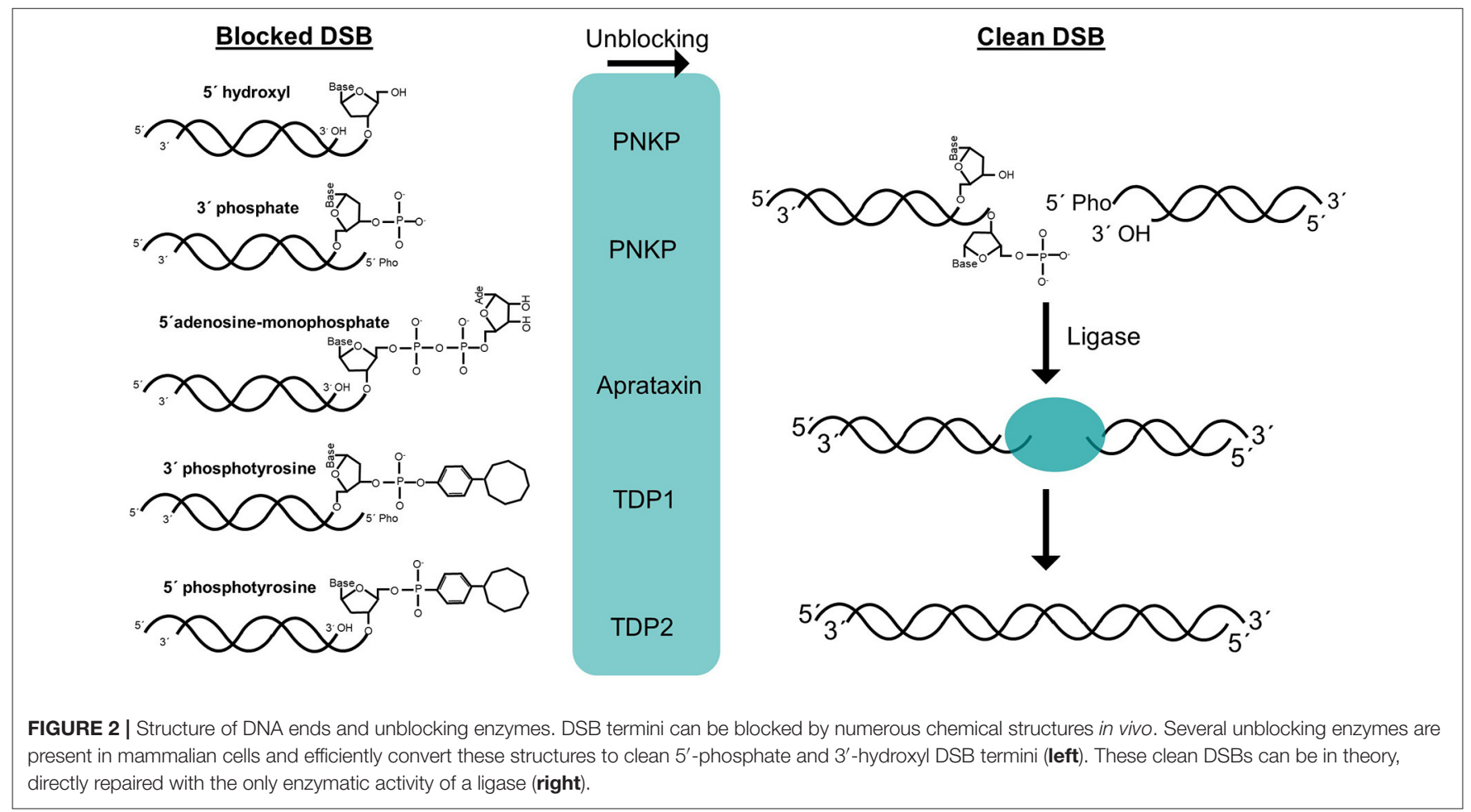

to resolution paths with the fewest number of enzymatic steps. This way, direct ligation is favored over more complex pathways that include end-processing and/or DNA synthesis (Waters et al., 2014). Consistent with this, LIG4 is the most flexible ligase known so far (Ma et al., 2004; Gu et al., 2007), and the differences in how their catalytic domains interact with different end structures trigger dramatic changes in the dynamics of the entire NHEJ complex, determining the steps taken to complete repair and the factors required (Conlin et al., 2017). A hierarchical order in the action of NHEJ components is also supported by the formation of a synapsis with two different stages (Graham et al., 2016). First, DNA ends are tethered sufficiently far apart, and are then closely aligned by DNA-PK, XLF, and the LIG4-XRCC4 complex. It has been suggested that this structural conversion can be coordinated with end-processing by changes in the phosphorylation profile of DNA-PKcs (Graham et al., 2016), which would provide a 
mechanism for the regulation of end processing and ligation. Although both models could seem contradictory, they may not be mutually exclusive. While, NHEJ could behave as an iterative process in which various components can be loaded and act in various combinations without an established order, providing flexibility and efficiency to the repair process, the decision of how complex ends are repaired should not be stochastically determined, as specific unblocking activities must be preferred over end-processing in order to avoid sequence modification.

\section{NUCLEASES IN NHEJ}

As mentioned above, under certain circumstances, DSBs require end processing by the action of nucleases. Usually, these nucleases remove chemical modifications and blockages or cleave mismatched ends by trimming $5^{\prime}$ or $3^{\prime}$ termini through exo- and/or endonucleolytic processing to expose short regions of microhomology between strands and promote end joining (Pannunzio et al., 2018). ARTEMIS is the major nuclease implicated in end-processing during NHEJ (Ma et al., 2002; Goodarzi et al., 2006; Yannone et al., 2008). Its main role takes place during $\mathrm{V}(\mathrm{D}) \mathrm{J}$ recombination, where it is responsible for the opening of DNA hairpins formed at coding joints, an endonucleolytic activity that is promoted by phosphorylation in the $\mathrm{ABCDE}$ cluster of DNA-PKcs. However, it has been also shown to have DNA-PKcs-independent $5^{\prime}$ exonuclease activity on ssDNA (Pawelczak and Turchi, 2010; Li et al., 2014). Beyond its role in $\mathrm{V}(\mathrm{D}) \mathrm{J}$ recombination, ARTEMIS contribution in NHEJ is still under study, and recent analysis demonstrated that the ARTEMIS-DNA-PKcs complex also promotes the ligation of incompatible overhangs in vitro (Chang et al., 2016; Pannunzio et al., 2018). Besides its versatility to act at many different types of DNA ends, there is a common feature in all ARTEMIS substrates: a ss-dsDNA boundary, which is present in a wide variety of different DNA end configurations (Chang et al., 2015; Chang and Lieber, 2016). Interestingly, a novel $3^{\prime}$ endonuclease activity of ARTEMIS has been recently described, that is promoted by XRCC4-LIG4 complex and also independent of DNA-PKcs (Gerodimos et al., 2017). The stimulation of this activity could be as a result of a conformational change due to the interaction with LIG4 (Pannunzio et al., 2018).

Another factor involved in the repair of complex ends requiring end processing is the MRE11 protein from the MRN complex (consisting of MRE11, RAD50, and NBS1). The MRN complex acts as a sensor of DSBs and promotes repair by NHEJ or HR. Specifically, MRE11 exhibits $3^{\prime}-5^{\prime}$ exonuclease and singlestranded and DNA hairpin endonuclease activities (Paull and Gellert, 1998; Trujillo et al., 2003; Lisby et al., 2004; Stracker and Petrini, 2011; Williams et al., 2011). Endonucleolytic cleavage may be of particular importance for DNA ends covalentlybound to Spo11 (Neale et al., 2005), terminated by hairpins (Lobachev et al., 2002) or generated by TOP1 and 2 poisons (Hartsuiker et al., 2009; Quennet et al., 2011; Hoa et al., 2016). Furthermore, recent in vitro studies described that NBS1 is essential to promote MRE11 nuclease activities on DNA ends containing protein adducts, while it inhibits MRE11 $3^{\prime}$ to $5^{\prime}$ exonuclease degradation of clean ends (Deshpande et al., 2016). Additionally, the function of the MRN complex during resection is stimulated by the phosphorylated form of CTIP (Anand et al., 2016). Remarkably, the nuclease activity of CTIP has been reported to be specifically required for processing complex DSBs, such as those harboring topoisomerase adducts or generated by irradiation. This suggests that the endonuclease activity of CTIP is only necessary for the removal of DNA adducts and not for the resection of unmodified DNA breaks (Makharashvili et al., 2014). This differentiates catalytic and non-catalytic functions of CTIP during end resection, which requirement would be end-structure dependent.

\section{POLYMERASES IN NHEJ}

As mentioned above, as a consequence of the processing of complex DSBs, the participation of other accessory factors such as DNA polymerases of the PolX family is often required. These polymerases are especially suited for filling in the small gaps that are generated when two ssDNA protruding ends with the same polarity and have either none or partial complementarity. The action of the different PolX polymerases during NHEJ seems to be determined by a gradient of template strand dependence after DSB ends are synapsed, with Pol $\lambda$ being completely template-dependent, Pol $\mu$ having some template requirements and Terminal Deoxynucleotidyl Transferase (TdT) being fully template-independent (McElhinny et al., 2005). Therefore, when $3^{\prime}$-protruding ends at DSBs do not have any complementarity with each other, Pol $\mu$ and TdT polymerases can add nucleotides for generating de novo terminal microhomology at DNA ends (Gu et al., 2007; Davis et al., 2008; Chang et al., 2016). PolX polymerases are recruited to DSBs through the specific interaction between their BRCT domains with NHEJ core factors (Mueller et al., 2008; Boubakour-Azzouz et al., 2012; Malu et al., 2012; Craxton et al., 2018). These interactions favor DSB repair efficiency (Tseng and Tomkinson, 2002; Craxton et al., 2018), and can be facilitated to some extent by DNA-PKcs-mediated phosphorylation (Sastre-Moreno et al., 2017). In fact, systematic analyses to determine how overhang sequence affects the activity of NHEJ polymerases has shown some DNA synthesis patterns that may be coordinated with ligation complex capabilities (Craxton et al., 2018).

\section{END-PROTECTING FACTORS}

In addition to all these unblocking and processing factors, other accessory NHEJ components are required to inhibit or restrict degradation of DSB ends, and therefore avoid excessive DNA sequence loss. In this regard, modifications at the chromatin flanking the DSB, such as histone H2AX phosphorylation (Helmink et al., 2011), and the subsequent recruitment of downstream factors of the DNA damage response (DDR), such as MDC1, 53BP1, and BRCA1 (Bekker-Jensen and Mailand, 2010) represent crucial events for the choice of proper repair pathways, regulating to which extent DSB ends are processed. Accordingly, $\mathrm{H} 2 \mathrm{AX}$ deficient mice show an increase in genome instability and, 
in the absence of P53, are prone to tumor development (Celeste et al., 2002, 2003; Bassing et al., 2003). Moreover, in ARTEMIS deficient cells, $\mathrm{H} 2 \mathrm{AX}$ was reported to limit the processing of DNA ends by CTIP endonuclease upon induction of blocked DSBs during V(D)J recombination, this function of H2AX being mediated by MDC1 (Helmink et al., 2011). In the same way, 53BP1 has been also shown to regulate end-processing during $\mathrm{V}(\mathrm{D}) \mathrm{J}$ and CSR recombination (Difilippantonio et al., 2008; Bothmer et al., 2010) and to inhibit CTIP-dependent resection in BRCA1 deficient cells at post-replicative stages of cell cycle, suggesting that $\mathrm{H} 2 \mathrm{AX}$ phosphorylation may restrict resection by the recruitment of 53BP1 (Bunting et al., 2010). The protective role of DNA ends by 53BP1 requires the participation of some downstream factors, such as PTIP (Kurimasa et al., 2015) and RIF1 (Kienker, 2000; Lee K. J. et al., 2004; Douglas et al., 2005), and maybe other factors yet to be discovered. In this regard, the recently discovered ssDNA-binding complex shieldin has been proposed to act as ultimate effector of the 53BP-RIF1 pathway for end protection (Chan et al., 2002; Ding et al., 2003; Meek et al., 2007). Of note, ARTEMIS was previously identified as a PTIP-binding protein, and, strikingly, as one of main downstream effectors of 53BP1-PTIP pathway (Wang et al., 2014). This suggests that 53BP1 could be promoting limited endtrimming and the repair of DSBs through NHEJ, and therefore directly competing with the HR repair pathway that would entail long resection.

\section{DNA-PKcS, A MASTER REGULATOR OF ACCESS TO DSB ENDS}

Despite not being conserved in lower eukaryotes, the activity of this phosphatidylinosytol 3-kinase-related kinase (PI3KK) is a clear requisite for its functioning during NHEJ in mammalian cells (Kienker, 2000; Kurimasa et al., 2015). Although there is a long list of DNA-PKcs substrates, mutational analysis (Lee K. J. et al., 2004; Douglas et al., 2005; Goodarzi et al., 2006; Meek et al., 2008) concludes that DNA-PKcs itself is the only NHEJ factor that has been shown to be a functionally relevant target of its own kinase activity (Chan et al., 2002; Ding et al., 2003; Soubeyrand et al., 2003; Cui et al., 2005; Douglas et al., 2007; Meek et al., 2007, 2008). The most well-accepted consequence of such DNA-PKcs autophosphorylation is its inactivation and dissociation from DNA ends, allowing subsequent joining by LIG4 (Chan and Lees-Miller, 1996; Douglas et al., 2001). Despite the fact that DNA end binding by DNA-PKcs is indifferent to distinct DNA end structures, some studies indicate that cisplatinDNA adducts near the ends reduce kinase activation, suggesting that free termini could be involved in the activation of DNA-PKcs (Turchi, 2000; Pawelczak et al., 2005). It has been suggested that kinase activation occurs in trans, linking autophosphorylation of DNA-PKcs to synapsis. Although this point is still a matter of debate, this may provide an important mechanism by which DNA-PKcs protects DNA-ends to maintain genomic integrity. However, extensive studies have shown that in response to DSBs, DNA-PKcs autophosphorylation can occur in different residues, with each event having specific functional consequences (Meek et al., 2008; Davis et al., 2014). In human DNA-PKcs, amino acid clusters known as ABCDE, flanking Thr2609 residue, and PQR, around the Ser2056 residue, are the two major phosphorylation sites (Ding et al., 2003; Block et al., 2004; Reddy et al., 2004; Cui et al., 2005; Meek et al., 2007). Although both clusters can be autophosphorylated by DNA-PKcs itself, the ABCDE cluster can be also phosphorylated by ATM or ATR under different cellular stresses (Chen et al., 2007; Meek et al., 2008; Davis et al., 2010). Site-directed mutagenesis analyses and characterization of animal models of DNA-PKcs deficiency (Blunt et al., 1996; Araki et al., 1997; Taccioli et al., 1998; Beamish et al., 2000; Zhang et al., 2011; Danska et al., 2015; Jiang et al., 2015) have revealed that the specific defect resulting from blocking either $\mathrm{ABCDE}$ or $\mathrm{PQR}$ phosphorylation is DNA end processing deregulation. Both clusters show antagonistic functions, and whereas phosphorylation in the $\mathrm{ABCDE}$ cluster promotes DNA end processing, phosphorylation of sites within the $\mathrm{PQR}$ cluster inhibits DNA end resection. Specifically, the ABCDE cluster is reported to promote end processing by regulating the access of ARTEMIS to the ends (Ma et al., 2002; Cui et al., 2005; Goodarzi et al., 2006; Yannone et al., 2008). On the other hand, end-ligation requires a strict DNA-PKcs autophosphorylation, possibly in the PQR cluster, which is promoted by ligatable ends and synapsis. This way, possible unsuccessful ligation attempts are avoided. Thus, DNA-PKcs can be considered a molecular shift that coordinates end processing and ligation through its phosphorylation to maximize the efficiency of the NHEJ pathway.

\section{ATM, A KEY FACTOR TO ORCHESTRATE END PROCESSING}

Ataxia Telangiectasia Mutated (ATM) kinase is another member of the PI3KK family, recognized by its function as an apical activator of the DDR in response to DSBs (McKinnon, 2004). Interestingly, the structure of ends is a crucial factor which determines the requirement of ATM for the repair of a DSB (Álvarez-Quilón et al., 2014). Specifically, ATM exclusively facilitates the repair of irreversibly blocked TOP2mediated DSBs, arising by etoposide treatment in TDP2deficient background (Álvarez-Quilón et al., 2014). Consistent with this, ATM-mediated repair promotes cell survival and the maintenance of genome integrity, avoiding micronuclei and chromosomal aberration formation after the induction of DSBs harboring termini that require end processing (Álvarez-Quilón et al., 2014). Although the underlying molecular mechanisms by which ATM deals with blocked DNA ends are still unclear, two complementary explanations have been proposed (ÁlvarezQuilón et al., 2014). On the one hand, ATM can promote limited resection to eliminate the complex structures at DSB ends through the action of nucleases. In this regard, ATM phosphorylates ARTEMIS and DNA-PKcs at the ABCDE cluster (see above) (Chen et al., 2007; Meek et al., 2008; Davis et al., 2010). In addition, a functional interplay between ATM and the MRN complex has been widely reported. Indeed, the three components of the complex are all phosphorylated by ATM, which has been proposed as a modulator of its processing activity 
(Kijas et al., 2015). Then, the MRN complex interacts with CtIP, which is also positively regulated by ATM to promote endresection (You and Bailis, 2010; Wang et al., 2013). Finally, ATM regulates other nucleases that could be involved in resolving incompatible ends. This includes APLF (Aprataxin and PNKPlike factor) (Macrae et al., 2008; Fenton et al., 2013); DNA replication helicase/nuclease 2 (DNA2) (Paudyal et al., 2017) or EXO1 (Bolderson et al., 2010; Tomimatsu et al., 2017). On the other hand, ATM could restrict excessive nucleolytic degradation of DNA ends (Rahal et al., 2008). This can actually operate by a direct inhibitory action on aforementioned nucleases such as MRE11 (Rahal et al., 2010) or EXO1 (Bolderson et al., 2010), and/or by promoting modifications at the chromatin flanking the DSB and the recruitment of protecting factors. In this regard, the protective function of $\mathrm{H} 2 \mathrm{AX}$ depends on its phosphorylation at Ser139 to form $\gamma$-H2AX in chromatin flanking DNA DSBs (Helmink et al., 2011), which is preferentially carried out by ATM (Takahashi et al., 2010). The $\gamma$-H2AX downstream factor MDC1 is also phosphorylated by ATM, promoting its oligomerization and spreading on chromatin (Maréchal and Zou, 2013). In addition, ATM phosphorylates 53BP1 (Anderson et al., 2002; Jowsey et al., 2007) and these phosphorylations are required for 53BP1 interaction with PTIP (Munoz et al., 2007) and RIF1 (Chapman et al., 2013). Finally, in addition to these dual end processing/-protective roles, ATM could operate at a later stage in the repair process. For example, after ionizing radiation-induced DSBs, ATM phosphorylates Pol $\lambda$, which would promote conformational changes in Pol $\lambda$

\section{REFERENCES}

Álvarez-Quilón, A., Serrano-Benítez, A., Lieberman, J. A., Quintero, C., SánchezGutiérrez, D., Escudero, L. M., et al. (2014). ATM specifically mediates repair of double-strand breaks with blocked DNA ends. Nat. Commun. 5:3347. doi: $10.1038 /$ ncomms 4347

Anand, R., Ranjha, L., Cannavo, E., and Cejka, P. (2016). Phosphorylated CtIP functions as a co-factor of the MRE11-RAD50-NBS1 endonuclease in DNA end resection. Mol. Cell 64, 940-950. doi: 10.1016/j.molcel.2016.10.017

Anderson, L., Henderson, C., and Adachi, Y. (2002). Phosphorylation and Rapid Relocalization of 53BP1 to nuclear foci upon DNA damage. Mol. Cell. Biol. 21, 1719-1729. doi: 10.1128/MCB.21.5.1719-1729.2001

Andres, S. N., Schellenberg, M. J., Wallace, B. D., Tumbale, P., and Scott Williams, R. (2015). Recognition and repair of chemically heterogeneous structures at DNA ends. Environ. Mol. Mutagen. 56, 1-21. doi: 10.1002/em.21892

Araki, R., Fujimori, A., Hamatani, K., Mita, K., Saito, T., Mori, M., et al. (1997). Nonsense mutation at Tyr-4046 in the DNA-dependent protein kinase catalytic subunit of severe combined immune deficiency mice. Proc. Natl. Acad. Sci. U.S.A. 94, 2438-2443. doi: 10.1073/pnas.94.6.2438

Bassing, C. H., Suh, H., Ferguson, D. O., Chua, K. F., Manis, J., Eckersdorff, M., et al. (2003). Histone H2AX: a dosage-dependent suppressor of oncogenic translocations and tumors. Cell. 114, 359-370. doi: 10.1016/s0092-8674(03)00566-x

Beamish, H. J., Jessberger, R., Riballo, E., Priestley, A., Blunt, T., Kysela, B., et al. (2000). The C-terminal conserved domain of DNA-PKcs, missing in the SCID mouse, is required for kinase activity. Nucleic Acids Res. 28, 1506-1513. doi: 10.1093/nar/28.7.1506

Bekker-Jensen, S., and Mailand, N. (2010). Assembly and function of DNA doublestrand break repair foci in mammalian cells. DNA Repair. 9, 1219-1228. doi: 10.1016/j.dnarep.2010.09.010 that facilitate its interaction with NHEJ core factors at DSBs and, hence, stimulates gap-filling DNA synthesis during NHEJ (Sastre-Moreno et al., 2017).

The structure and conformation of DNA ends are therefore determinant to the repair process and outcome, especially in situations in which end-joining mechanisms are prevalent. Although many of the enzymatic activities required have been identified and characterized in detail, the mechanisms by which cells regulate and integrate these activities to keep sequence variation under control are still poorly understood. In this sense, it is tempting to think on blocked DSBs and a deregulated cellular response to these lesions as important threats to genome integrity, and, potentially, drivers of malignant transformation and cancer.

\section{AUTHOR CONTRIBUTIONS}

AS-B, FC-L, and JR conceived and wrote the manuscript.

\section{ACKNOWLEDGMENTS}

Work in the FC-L laboratory was funded with grants from the Spanish and Andalusian Government (SAF2017-89619-R, CVI-7948, European Regional Development Fund), and the European Research Council (ERC-CoG-2014-647359); and with an individual fellowship for AS-B (Beca Predoctoral AEFAT, Asociación Española Familia Ataxia Telangiectasia). CABIMER was supported by the Andalusian Government.

Block, W. D., Yu, Y., Merkle, D., Gifford, J. L., Ding, Q., Meek, K., et al. (2004). Autophosphorylation-dependent remodeling of the DNA-dependent protein kinase catalytic subunit regulates ligation of DNA ends. Nucleic Acids Res. 32, 4351-4357. doi: 10.1093/nar/gkh761

Blunt, T., Gell, D., Fox, M., Taccioli, G. E., Lehmann, A. R., Jackson, S. P., et al. (1996). Identification of a nonsense mutation in the carboxyl-terminal region of DNA-dependent protein kinase catalytic subunit in the scid mouse. Proc. Natl. Acad. Sci. U.S.A. 93, 10285-10290. doi: 10.1073/pnas.93.19.10285

Bolderson, E., Tomimatsu, N., Richard, D. J., Boucher, D., Kumar, R., Pandita, T. K., et al. (2010). Phosphorylation of Exol modulates homologous recombination repair of DNA double-strand breaks. Nucleic Acids Res. 38, 1821-1831. doi: 10.1093/nar/gkp1164

Bothmer, A., Robbiani, D. F., Feldhahn, N., Gazumyan, A., Nussenzweig, A., and Nussenzweig, M. C. (2010). 53BP1 regulates DNA resection and the choice between classical and alternative end joining during class switch recombination. J. Exp. Med. 207, 855-865. doi: 10.1084/jem.20100244

Boubakour-Azzouz, I., Bertrand, P., Claes, A., Lopez, B. S., and Rougeon, F. (2012). Terminal deoxynucleotidyl transferase requires KU80 and XRCC4 to promote $\mathrm{N}$-addition at non-V(D)J chromosomal breaks in non-lymphoid cells. Nucleic Acids Res. 40, 8381-8391. doi: 10.1093/nar/gks585

Bunting, S. F., Callén, E., Wong, N., Chen, H. T., Polato, F., Gunn, A., et al. (2010). 53BP1 inhibits homologous recombination in brca1deficient cells by blocking resection of DNA breaks. Cell 141, 243-254. doi: 10.1093/med/9780199204854.003.0401

Capp, J. P., Boudsocq, F., Besnard, A. G., Lopez, B. S., Cazaux, C., Hoffmann, J. S., et al. (2007). Involvement of DNA polymerase mu in the repair of a specific subset of DNA double-strand breaks in mammalian cells. Nucleic Acids Res. 35, 3551-3560. doi: 10.1093/nar/gkm243

Celeste, A., Difilippantonio, S., Difilippantonio, M. J., Fernandez-Capetillo, O., Pilch, D. R., Sedelnikova, O. A., et al. (2003). H2AX haploinsufficiency 
modifies genomic stability and tumor susceptibility. Cell 114, 371-383. doi: 10.1016/s0092-8674(03)00567-1

Celeste, A., Petersen, S., Romanienko, P. J., Fernandez-Capetillo, O., Chen, H. T., Sedelnikova, O. A., et al. (2002). Genomic instability in mice lacking histone H2AX. Science 296, 922-977. doi: 10.1126/science.1069398

Chan, D. W., Chen, B. P. C., Prithivirajsingh, S., Kurimasa, A., Story, M. D., Qin, J., et al. (2002). Autophosphorylation of the DNA-dependent protein kinase catalytic subunit is required for rejoining of DNA double-strand breaks. Genes Dev. 16, 2333-2338. doi: 10.1101/gad.1015202

Chan, D. W., and Lees-Miller, S. P. (1996). The DNA-dependent protein kinase is inactivated by autophosphorylation of the catalytic subunit. J. Biol. Chem. 271, 8936-8941. doi: 10.1074/jbc.271.15.8936

Chang, H. H. Y., and Lieber, M. R. (2016). Structure-specific nuclease activities of Artemis and the Artemis: DNA-PKcs complex. Nucleic Acids Res. 44, 4991-4997. doi: 10.1093/nar/gkw456

Chang, H. H. Y., Watanabe, G., Gerodimos, C. A., Ochi, T., Blundell, T. L., Jackson, S. P., et al. (2016). Different DNA end configurations dictate which NHEJ components are most important for joining efficiency. J. Biol. Chem. 291, 24377-24389. doi: 10.1074/jbc.M116.752329

Chang, H. H. Y., Watanabe, G., and Lieber, M. R. (2015). Unifying the DNA end-processing roles of the artemis nuclease: Ku-dependent artemis resection at blunt DNA ends. J. Biol. Chem. 290, 24036-24050. doi: 10.1074/jbc.M115.680900

Chapman, J. R., Barral, P., Vannier, J. B., Borel, V., Steger, M., Tomas-Loba, A., et al. (2013). RIF1 is essential for 53BP1-dependent nonhomologous end joining and suppression of DNA double-strand break resection. Mol. Cell 49, 858-871. doi: 10.1016/j.molcel.2013.01.002

Chen, B. P. C., Uematsu, N., Kobayashi, J., Lerenthal, Y., Krempler, A., Yajima, H., et al. (2007). Ataxia telangiectasia mutated (ATM) is essential for DNA-PKcs phosphorylations at the Thr-2609 cluster upon DNA double strand break. J. Biol. Chem. 282, 6582-6587. doi: 10.1074/jbc.M611605200

Conlin, M. P., Reid, D. A., Small, G. W., Chang, H. H., Watanabe, G., Lieber, M. R., et al. (2017). DNA Ligase IV guides end-processing choice during nonhomologous end joining. Cell Rep. 20, 2810-2819. doi: 10.1016/j.celrep.2017.08.091

Craxton, A., Munnur, D., Jukes-Jones, R., Skalka, G., Langlais, C., Cain, K., et al. (2018). PAXX and its paralogs synergistically direct DNA polymerase $\lambda$ activity in DNA repair. Nat. Commun. 9:3877. doi: 10.1038/s41467-018-06127-y

Cui, X., Yu, Y., Gupta, S., Cho, Y.-M., Lees-Miller, S. P., and Meek, K. (2005). Autophosphorylation of DNA-dependent protein kinase regulates DNA end processing and may also alter double-strand break repair pathway choice. Mol. Cell. Biol. 25, 10842-10852. doi: 10.1128/MCB.25.24.10842-10852.2005

Danska, J. S., Holland, D. P., Mariathasan, S., Williams, K. M., and Guidos, C. J. (2015). Biochemical and genetic defects in the DNA-dependent protein kinase in murine scid lymphocytes. Mol. Cell. Biol. 16, 5507-5517. doi: $10.1128 / \mathrm{mcb} \cdot 16.10 .5507$

Davis, A. J., Chen, B. P. C., and Chen, D. J. (2014). DNA-PK: a dynamic enzyme in a versatile DSB repair pathway. DNA Repair 17, 21-29. doi: 10.1016/j.dnarep.2014.02.020

Davis, A. J., So, S., and Chen, D. J. (2010). Dynamics of the PI3K-like protein kinase members ATM and DNA-PKcs at DNA double strand breaks. Cell Cycle 9, 2529-2536. doi: 10.4161/cc.9.13.12148

Davis, B. J., Havener, J. M., and Ramsden, D. A. (2008). End-bridging is required for pol mu to efficiently promote repair of noncomplementary ends by nonhomologous end joining. Nucleic Acids Res. 36, 3085-3094. doi: $10.1093 / \mathrm{nar} / \mathrm{gkn} 164$

Deshpande, R. A., Lee, J. H., Arora, S., and Paull, T. T. (2016). Nbs1 converts the human Mre11/Rad50 nuclease complex into an endo/exonuclease machine specific for protein-DNA adducts. Mol. Cell 64, 593-606. doi: 10.1016/j.molcel.2016.10.010

Difilippantonio, S., Gapud, E., Wong, N., Huang, C. Y., Mahowald, G., Chen, H. T., et al. (2008). 53BP1 facilitates long-range DNA end-joining during $\mathrm{V}(\mathrm{D}) \mathrm{J}$ recombination. Nature 456, 529-533. doi: 10.1038/nature 07476

Ding, Q., Reddy, Y. V. R., Wang, W., Woods, T., Douglas, P., Ramsden, D. A., et al. (2003). Autophosphorylation of the catalytic subunit of the DNA-dependent protein kinase is required for efficient end processing during DNA double-strand break repair. Mol. Cell. Biol. 23, 5836-5848. doi: $10.1128 / \mathrm{mcb} .23 .16 .5836-5848.2003$

Douglas, P., Cui, X., Block, W. D., Yu, Y., Gupta, S., Ding, Q., et al. (2007). The DNA-dependent protein kinase catalytic subunit is phosphorylated in vivo on threonine 3950, a highly conserved amino acid in the protein kinase domain. Mol. Cell. Biol. 27, 1581-1591. doi: 10.1128/MCB.01962-06

Douglas, P., Gupta, S., Morrice, N., Meek, K., and Lees-Miller, S. P. (2005). DNA-PK-dependent phosphorylation of $\mathrm{Ku} 70 / 80$ is not required for non-homologous end joining. DNA Repair 4, 1006-1018. doi: 10.1016/j.dnarep.2005.05.003

Douglas, P., Moorhead, G. B. G., Ye, R., and Lees-Miller, S. P. (2001). Protein phosphatases regulate DNA-dependent protein kinase activity. J. Biol. Chem. 276, 18992-18998. doi: 10.1074/jbc.M011703200

Fenton, A. L., Shirodkar, P., MacRae, C. J., Meng, L., and Anne Koch, C. (2013). The PARP3- and ATM-dependent phosphorylation of APLF facilitates DNA double-strand break repair. Nucleic Acids Res. 41, 4080-4092. doi: $10.1093 /$ nar/gkt134

Gerodimos, C. A., Chang, H. H. Y., Watanabe, G., and Lieber, M. R. (2017). Effects of DNA end configuration on XRCC4-DNA ligase IV and its stimulation of Artemis activity. J. Biol. Chem. 292, 13914-13924. doi: 10.1074/jbc.M117.798850

Goodarzi, A. A., Yu, Y., Riballo, E., Douglas, P., Walker, S. A., Ye, R., et al. (2006) DNA-PK autophosphorylation facilitates Artemis endonuclease activity. EMBO J. 25, 3880-3889. doi: 10.1038/sj.emboj.7601255

Graham, T. G. W., Walter, J. C., and Loparo, J. J. (2016). Two-stage synapsis of DNA ends during non-homologous end joining. Mol. Cell. 61, 850-858. doi: 10.1016/j.molcel.2016.02.010

Gu, J., Li, S., Zhang, X., Wang, L. C., Niewolik, D., Schwarz, K., et al. (2010). DNAPKcs regulates a single-stranded DNA endonuclease activity of Artemis. DNA Repair 9, 429-437. doi: 10.1016/j.dnarep.2010.01.001

Gu, J., and Lieber, M. R. (2008). Mechanistic flexibility as a conserved theme across 3 billion years of nonhomologous DNA end-joining. Genes Dev. 22, 411-415. doi: $10.1101 /$ gad.1646608

Gu, J., Lu, H., Tippin, B., Shimazaki, N., Goodman, M. F., and Lieber, M. R. (2007). XRCC4:DNA ligase IV can ligate incompatible DNA ends and can ligate across gaps. EMBO J. 26, 1010-1023. doi: 10.1038/sj.emboj.7601559

Hartsuiker, E., Neale, M. J., and Carr, A. M. (2009). Distinct requirements for the Rad32(Mre11) nuclease and Ctp1(CtIP) in the removal of covalently bound topoisomerase I and II from DNA. Mol. Cell. 33, 117-123. doi: 10.1016/j.molcel.2008.11.021

Helmink, B. A., Tubbs, A. T., Dorsett, Y., Bednarski, J. J., Walker, L. M., Feng, Z., et al. (2011). H2AX prevents CtIP-mediated DNA end resection and aberrant repair in G1-phase lymphocytes. Nature 469, 245-249. doi: $10.1038 /$ nature 09585

Hoa, N. N., Shimizu, T., Zhou, Z. W., Wang, Z. Q., Deshpande, R. A., Paull, T. T., et al. (2016). Mre11 is essential for the removal of lethal topoisomerase 2 covalent cleavage complexes. Mol. Cell. 64:1010. doi: 10.1016/j.molcel.2016.11.028

Jiang, W., Crowe, J. L., Liu, X., Nakajima, S., Wang, Y., Li, C., et al. (2015). Differential phosphorylation of DNA-PKcs regulates the interplay between end-processing and end-ligation during nonhomologous end-joining. Mol. Cell. 58, 172-185. doi: 10.1016/j.molcel.2015.02.024

Johnson, R. D. (2000). Sister chromatid gene conversion is a prominent doublestrand break repair pathway in mammalian cells. EMBO J. 19, 3398-3407. doi: 10.1093/emboj/19.13.3398

Jowsey, P., Morrice, N. A., Hastie, C. J., McLauchlan, H., Toth, R., and Rouse, J. (2007). Characterisation of the sites of DNA damage-induced 53BP1 phosphorylation catalysed by ATM and ATR. DNA Repair 6, 1536-1544. doi: 10.1016/j.dnarep.2007.04.011

Kakarougkas, A., and Jeggo, P. A. (2014). DNA DSB repair pathway choice: an orchestrated handover mechanism. Br. J. Radiol. 87:20130685. doi: 10.1259/bjr.20130685

Kienker, L. J. (2000). Both V(D)J recombination and radioresistance require DNAPK kinase activity, though minimal levels suffice for $\mathrm{V}(\mathrm{D}) \mathrm{J}$ recombination. Nucleic Acids Res. 28, 2752-2761. doi: 10.1093/nar/28.14.2752

Kijas, A. W., Lim, Y. C., Bolderson, E., Cerosaletti, K., Gatei, M., Jakob, B., et al. (2015). ATM-dependent phosphorylation of MRE11 controls extent of 
resection during homology directed repair by signalling through Exonuclease 1. Nucleic Acids Res. 43, 8352-8367. doi: 10.1093/nar/gkv754

Kurimasa, A., Kumano, S., Boubnov, N. V., Story, M. D., Tung, C.-S., Peterson, S. R., et al. (2015). Requirement for the kinase activity of human DNA-dependent protein kinase catalytic subunit in DNA strand break rejoining. Mol. Cell. Biol. 19, 3877-3884. doi: 10.1128/mcb.19.5.3877

Lee, J. W., Blanco, L., Zhou, T., Garcia-Diaz, M., Bebenek, K., Kunkel, T. A., et al. (2004). Implication of DNA polymerase lambda in alignment-based gap filling for nonhomologous DNA end joining in human nuclear extracts. J. Biol. Chem. 279, 805-811. doi: 10.1074/jbc.M307913200

Lee, K. J., Jovanovic, M., Udayakumar, D., Bladen, C. L., and Dynan, W. S. (2004). Identification of DNA-PKcs phosphorylation sites in XRCC4 and effects of mutations at these sites on DNA end joining in a cell-free system. DNA Repair 3, 267-276. doi: 10.1016/j.dnarep.2003.11.005

Li, S., Chang, H. H., Niewolik, D., Hedrick, M. P., Pinkerton, A. B., Hassig, C. A., et al. (2014). Evidence that the DNA endonuclease ARTEMIS also has intrinsic 5'-exonuclease activity. J. Biol. Chem. 289, 7825-7834. doi: $10.1074 /$ jbc.M113.544874

Lieber, M. R. (2008). The mechanism of human nonhomologous DNA end joining. J. Biol. Chem. 283, 1-5. doi: 10.1074/jbc.R700039200

Lieber, M. R. (2010). The mechanism of double-strand DNA break repair by the nonhomologous DNA end-joining pathway. Annu. Rev. Biochem. 79, 181-211. doi: 10.1146/annurev.biochem.052308.093131

Lisby, M., Barlow, J. H., Burgess, R. C., and Rothstein, R. (2004). Choreography of the DNA damage response: spatiotemporal relationships among checkpoint and repair proteins. Cell 118, 699-713. doi: 10.1016/j.cell.2004.08.015

Lobachev, K. S., Gordenin, D. A., and Resnick, M. A. (2002). The Mre11 complex is required for repair of hairpin-capped double-strand breaks and prevention of chromosome rearrangements. Cell 108, 183-193. doi: 10.1016/s0092-8674(02)00614-1

Ma, Y., Lu, H., Tippin, B., Goodman, M. F., Shimazaki, N., Koiwai, O., et al. (2004). A biochemically defined system for mammalian nonhomologous DNA end joining. Mol. Cell. 16, 701-713. doi: 10.1016/j.molcel.2004.11.017

Ma, Y., Pannicke, U., Schwarz, K., and Lieber, M. R. (2002). Hairpin opening and overhang processing by an Artemis/DNA-dependent protein kinase complex in nonhomologous end joining and V(D)J recombination. Cell 108, 781-794. doi: 10.1016/s0092-8674(02)00671-2

Macrae, C. J., McCulloch, R. D., Ylanko, J., Durocher, D., and Koch, C. A. (2008). APLF (C2orf13) facilitates nonhomologous end-joining and undergoes ATMdependent hyperphosphorylation following ionizing radiation. DNA Repair 7, 292-302. doi: 10.1016/j.dnarep.2007.10.008

Mahajan, K. N., Nick McElhinny, S. A., Mitchell, B. S., and Ramsden, D. A. (2002). Association of DNA polymerase mu (pol mu) with $\mathrm{Ku}$ and ligase IV: role for pol $\mathrm{mu}$ in end-joining double-strand break repair. Mol. Cell. Biol. 22, 5194-5202. doi: $10.1128 / \mathrm{mcb} .22 .14 .5194-5202.2002$

Makharashvili, N., Tubbs, A. T., Yang, S. H., Wang, H., Barton, O., Zhou, Y., et al. (2014). Catalytic and noncatalytic roles of the CtIP endonuclease in double-strand break end resection. Mol. Cell 54, 1022-1033. doi: 10.1016/j.molcel.2014.04.011

Malu, S., De Ioannes, P., Kozlov, M., Greene, M., Francis, D., Hanna, M., et al. (2012). Artemis C-terminal region facilitates V(D)J recombination through its interactions with DNA Ligase IV and DNA-PKcs. J. Exp. Med. 209, 955-963. doi: 10.1084 /jem.20111437

Maréchal, A., and Zou, L. (2013). DNA damage sensing by the ATM and ATR kinases. Cold Spring Harb. Perspect. Biol. 5:a012716. doi: 10.1101/cshperspect.a012716

McElhinny, S. A. N., Havener, J. M., Garcia-Diaz, M., Juárez, R., Bebenek, K., Kee, B. L., et al. (2005). A gradient of template dependence defines distinct biological roles for family X polymerases in nonhomologous end joining. Mol. Cell 19, 357-366. doi: 10.1016/j.molcel.2005.06.012

McKinnon, P. J. (2004). ATM and ataxia telangiectasia. EMBO Rep. 5, 772-776. doi: 10.1038/sj.embor.7400210

Meek, K., Dang, V., and Lees-Miller, S. P. (2008). DNA-PK: the means to justify the ends? Adv. Immunol. 99, 33-58. doi: 10.1016/S0065-2776(08)00602-0

Meek, K., Douglas, P., Cui, X., Ding, Q., and Lees-Miller, S. P. (2007). trans autophosphorylation at DNA-dependent protein kinase's two major autophosphorylation site clusters facilitates end processing but not end joining. Mol. Cell. Biol. 27, 3881-3890. doi: 10.1128/MCB.02366-06
Mueller, G. A., Moon, A. F., DeRose, E. F., Havener, J. M., Ramsden, D. A., Pedersen, L. C., et al. (2008). A comparison of BRCT domains involved in nonhomologous end-joining: introducing the solution structure of the BRCT domain of polymerase lambda. DNA Repair 7, 1340-1351. doi: 10.1016/j.dnarep.2008.04.018

Munoz, I. M., Jowsey, P. A., Toth, R., and Rouse, J. (2007). Phospho-epitope binding by the BRCT domains of hPTIP controls multiple aspects of the cellular response to DNA damage. Nucleic Acids Res. 35, 5312-5322. doi: $10.1093 / \mathrm{nar} / \mathrm{gkm} 493$

Neal, J. A., and Meek, K. (2011). Choosing the right path: does DNA-PK help make the decision? Mutat. Res. 711, 73-86. doi: 10.1016/j.mrfmmm.2011.02.010

Neale, M. J., Pan, J., and Keeney, S. (2005). Endonucleolytic processing of covalent protein-linked DNA double-strand breaks. Nature 436, 1053-1057. doi: $10.1038 /$ nature 03872

Ochi, T., Blackford, A. N., Coates, J., Jhujh, S., Mehmood, S., Tamura, N., et al. (2015). DNA repair. PAXX, a paralog of XRCC4 and XLF, interacts with $\mathrm{Ku}$ to promote DNA double-strand break repair. Science 347, 185-188. doi: $10.1126 /$ science. 1261971

Pannunzio, N. R., Watanabe, G., and Lieber, M. R. (2018). Nonhomologous DNA end-joining for repair of DNA double-strand breaks. J. Biol. Chem. 293, 10512-10523. doi: 10.1074/jbc.TM117.000374

Paudyal, S. C., Li, S., Yan, H., Hunter, T., and You, Z. (2017). Dna2 initiates resection at clean DNA double-strand breaks. Nucleic Acids Res. 45, 11766-11781. doi: 10.1093/nar/gkx830

Paull, T. T., and Gellert, M. (1998). The $3^{\prime}$ to $5^{\prime}$ exonuclease activity of Mre 11 facilitates repair of DNA double-strand breaks. Mol. Cell 1, 969-979. doi: 10.1016/s1097-2765(00) 80097-0

Pawelczak, K. S., Andrews, B. J., and Turchi, J. J. (2005). Differential activation of DNA-PK based on DNA strand orientation and sequence bias. Nucleic Acids Res. 33, 152-161. doi: 10.1093/nar/gki157

Pawelczak, K. S., and Turchi, J. J. (2010). Purification and characterization of exonuclease-free Artemis: Implications for DNA-PK-dependent processing of DNA termini in NHEJ-catalyzed DSB repair. DNA Repair 9, 670-677. doi: 10.1016/j.dnarep.2010.03.002

Povirk, L. F. (2012). Processing of damaged DNA ends for doublestrand break repair in mammalian cells. ISRN Mol. Biol. 2012:345805. doi: 10.5402/2012/345805

Quennet, V., Beucher, A., Barton, O., Takeda, S., and Löbrich, M. (2011). CtIP and MRN promote non-homologous end-joining of etoposide-induced DNA double-strand breaks in G1. Nucleic Acids Res. 39, 2144-2152. doi: 10.1093/nar/gkq1175

Rahal, E. A., Henricksen, L. A., Li, Y., Turchi, J. J., Pawelczak, K. S., and Dixon, K. (2008). ATM mediates repression of DNA end-degradation in an ATPdependent manner. DNA Repair 7, 464-475. doi: 10.1016/j.dnarep.2007.12.003

Rahal, E. A., Henricksen, L. A., Li, Y., Williams, R. S., Tainer, J. A., and Dixon, K. (2010). ATM regulates Mre11-dependent DNA enddegradation and microhomology-mediated end joining. Cell Cycle 9, 2866-2877. doi: 10.4161/cc.9.14.12363

Reddy, Y. V. R., Ding, Q., Lees-Miller, S. P., Meek, K., and Ramsden, D. A. (2004). Non-homologous end joining requires that the DNA-PK complex undergo an autophosphorylation-dependent rearrangement at DNA ends. J. Biol. Chem. 279, 39408-39413. doi: 10.1074/jbc.M406432200

Reid, D. A., Conlin, M. P., Yin, Y., Chang, H. H., Watanabe, G., Lieber, M. R., et al. (2017). Bridging of double-stranded breaks by the nonhomologous end-joining ligation complex is modulated by DNA end chemistry. Nucleic Acids Res. 45, 1872-1878. doi: 10.1093/nar/gkw1221

Reisz, J. A., Bansal, N., Qian, J., Zhao, W., and Furdui, C. M. (2014). Effects of ionizing radiation on biological molecules-mechanisms of damage and emerging methods of detection. Antioxid. Redox Signal. 21, 260-292. doi: 10.1089/ars.2013.5489

San Filippo, J., Sung, P., and Klein, H. (2008). Mechanism of eukaryotic homologous recombination. Ann. Rev. Biochem. 77, 229-257. doi: 10.1146/annurev.biochem.77.061306.125255

Sastre-Moreno, G., Pryor, J. M., Moreno-Oñate, M., Herrero-Ruiz, A. M., CortésLedesma, F., Blanco, L., et al. (2017). Regulation of human pol $\lambda$ by ATMmediated phosphorylation during non-homologous end joining. DNA Repair 51, 31-45. doi: 10.1016/j.dnarep.2017.01.004 
Soubeyrand, S., Pope, L., Pakuts, B., and Haché, R. J. G. (2003). Threonines $2638 / 2647$ in DNA-PK are essential for cellular resistance to ionizing radiation. Cancer Res. 63, 1198-1201.

Stracker, T. H., and Petrini, J. H. J. (2011). The MRE11 complex: starting from the ends. Nat. Rev. Mol. Cell Biol. 12, 90-103. doi: 10.1038/nrm3047

Strande, N. T., Waters, C. A., and Ramsden, D. A. (2012). Resolution of complex ends by Nonhomologous end joining - better to be lucky than good? Genome Integr. 3:10. doi: 10.1186/2041-9414-3-10

Taccioli, G. E., Amatucci, A. G., Beamish, H. J., Gell, D., Xiang, X. H., Torres Arzayus, M. I., et al. (1998). Targeted disruption of the catalytic subunit of the DNA-PK gene in mice confers severe combined immunodeficiency and radiosensitivity. Immunity 9, 355-366. doi: 10.1016/s1074-7613(00) 80618-4

Takahashi, A., Mori, E., Su, X., Nakagawa, Y., Okamoto, N., Uemura, H., et al. (2010). ATM is the predominant kinase involved in the phosphorylation of histone H2AX after heating. J. Radiat. Res. 51, 417-422. doi: 10.1269/jrr.10015

Tomimatsu, N., Mukherjee, B., Harris, J. L., Boffo, F. L., Hardebeck, M. C., Potts, P. R., et al. (2017). DNA-damage-induced degradation of EXO1 exonuclease limits DNA end resection to ensure accurate DNA repair. J. Biol. Chem. 292, 10779-10790. doi: 10.1074/jbc.M116.772475

Trujillo, K. M., Roh, D. H., Chen, L., Van Komen, S., Tomkinson, A., and Sung, P. (2003). Yeast xrs2 binds DNA and helps target rad50 and mre11 to DNA ends. J. Biol. Chem. 278, 48957-48964. doi: 10.1074/jbc.M309877200

Tseng, H. M., and Tomkinson, A. E. (2002). A physical and functional interaction between yeast Pol4 and Dnl4-Lif1 links DNA synthesis and ligation in nonhomologous end joining. J. Biol. Chem. 277, 45630-45637. doi: 10.1074/jbc.M206861200

Turchi, J. J. (2000). Cisplatin-DNA adducts inhibit translocation of the Ku subunits of DNA-PK. Nucleic Acids Res. 28, 4634-4641. doi: 10.1093/nar/28.23.4634

Wang, H., Shi, L. Z., Wong, C. C. L., Han, X., Hwang, P. Y. H., Truong, L. N., et al. (2013). The interaction of CtIP and Nbs1 connects $\mathrm{CDK}$ and ATM to regulate HR-mediated double-strand break repair. PLoS Genet. 9:e1003277. doi: 10.1371/journal.pgen. 1003277
Wang, J., Aroumougame, A., Lobrich, M., Li, Y., Chen, D., Chenj, J., et al. (2014) PTIP associates with artemis to dictate DNA repair pathway choice. Genes Dev. 28, 2693-2698. doi: 10.1101/gad.252478.114

Waters, C. A., Strande, N. T., Pryor, J. M., Strom, C. N., Mieczkowski, P., Burkhalter, M. D., et al. (2014). The fidelity of the ligation step determines how ends are resolved during nonhomologous end joining. Nat. Commun. 5:4286. doi: $10.1038 /$ ncomms5286

Williams, G. J., Williams, R. S., Williams, J. S., Moncalian, G., Arvai, A. S., Limbo, O., et al. (2011). ABC ATPase signature helices in Rad50 link nucleotide state to Mre11 interface for DNA repair. Nat Struct. Mol. Biol. 18, 423-431. doi: 10.1038/nsmb.2038

Yannone, S. M., Khan, I. S., Zhou, R. Z., Zhou, T., Valerie, K., and Povirk, L. F. (2008). Coordinate $5^{\prime}$ and $3^{\prime}$ endonucleolytic trimming of terminally blocked blunt DNA double-strand break ends by Artemis nuclease and DNA-dependent protein kinase. Nucleic Acids Res. 36, 3354-3365. doi: 10.1093/nar/gkn205

You, Z., and Bailis, J. M. (2010). DNA damage and decisions: CtIP coordinates DNA repair and cell cycle checkpoints. Trends Cell Biol. 20, 402-409. doi: $10.1016 /$ j.tcb.2010.04.002

Zhang, S., Yajima, H., Huynh, H., Zheng, J., Callen, E., Chen, H. T., et al. (2011). Congenital bone marrow failure in DNA-PKcs mutant mice associated with deficiencies in DNA repair. J. Cell Biol. 193, 295-305. doi: $10.1083 /$ jcb. 201009074

Conflict of Interest: The authors declare that the research was conducted in the absence of any commercial or financial relationships that could be construed as a potential conflict of interest.

Copyright (C) 2020 Serrano-Benitez, Cortés-Ledesma and Ruiz. This is an open-access article distributed under the terms of the Creative Commons Attribution License (CC $B Y)$. The use, distribution or reproduction in other forums is permitted, provided the original author(s) and the copyright owner(s) are credited and that the original publication in this journal is cited, in accordance with accepted academic practice. No use, distribution or reproduction is permitted which does not comply with these terms. 